\title{
Cultural and religious diversity in Hospice and Palliative care: A qualitative cross-country comparative analysis of the challenges of healthcare professionals.
}

\begin{abstract}
Background: Research has abundantly demonstrated a strong relationship between culture, religion and the experiences of death, dying, and bereavement. Consequently, cultural competence and a religiously sensitive practice have become highly relevant to social policies and professional practice. However, our current knowledge of culturally competent and religiously sensitive end of life care is primarily context specific, with little space for generalizability. Methods: This paper reports on findings from a qualitative comparative analysis of two nation specific studies that examined religious literacy and cultural competency, respectively, among palliative care professionals, drawing on similarities and attempting to identify further applicability of nation centred knowledge. Results: The study recognised six practice-based approaches in palliative and hospice care, when responding to cultural and religious or nonreligious identities of services users. These approaches intersect with each other via three organisational layers identified in the study; foundations, culture and professionals. Conclusions: Each identified practice-based approach seems to be incomplete when working with individuals for whom religion, belief and cultural identities are important. Change in practice is possible if all three organisational layers are considered simultaneously, while further research will shed more light about the benefits and challenges of each approach.
\end{abstract}

Keywords: religious literacy, cultural competence, hospice care, palliative care, cross-nationality

Wordcount: 7421

\section{Introduction}

Walter (2012) pointed out that literature comparing death practices across countries is sparse. He argued that global death practices are influenced by consequences of modernity such as urbanization and the division of labour, migration, rationality, the risk society, information technology, but also by nation specific history and culture. Hence, the management of death, dying and bereavement is characterized by a modern homogeneity, with culture- and nation-specific 
variations, which makes it challenging to generalize research findings across countries. In this paper, we seek to add to the existing pool of comparative literature on death, dying and bereavement by exploring the challenges faced by palliative care professionals across two nations; England and Denmark. The paper aims to open the conversation about how death, dying and bereavement are managed within institutional care, with a focus on cultural and religious contexts. Migration is identified as a strong influence that complicates the approaches and methods when working with service users (Thomsen, 2014; Pentaris, 2016). Bearing this in mind, the paper uses a qualitative comparative analysis of English and Danish methods of practice, seeking to explore palliative care professionals' approach to culture and religion while focusing on the challenges and barriers experienced as a result. To better contextualize this analysis, the following sections provide information regarding migration and its impact on current needs in palliative and hospice care in both countries.

\section{Migration: contextual similarities}

Both England and Denmark have experienced changes in their modern history as a consequence of migration and population diversity. The end of World War II and the economic upturn constituted a key moment in the history of migration for both countries, which resulted in the first migration wave in the 1950s and 1960s. The first wave was followed by a second wave as the families of the workers that had already migrated came to join them. In the first instance, neither country envisaged that migrants from the 1950s, 1960s, and 1970s would settle permanently but expected them to leave when they were no longer needed. The second wave of migration challenged this expectation (Timmins, 1995; Mikkelsen, 2008; Ejernæs, 2014). Since the 1980s, migration and cultural complexity have increased due to different push and pull factors resulting from wars, natural disasters and financial crises in different parts of the international community. 
The movements of populations into both countries continued over several decades, and especially in the 21st century (Hansen, 2003; Hickman, Mai, and Crowley, 2012). At the same time, debates developed about integration, citizenship and how societal structures would accommodate culture and religion specific needs across different spheres, e.g. employment and healthcare. Scant attention had been paid to accommodating different and varying identities in different spheres of society before the 1980s (Berger and Huntington, 2002). While the healthcare sector has already been explored in this context (Rechel et al., 2011; Altschuler, 2016), this paper is concerned primarily with palliative and hospice care.

\section{Adapting to changing cultural and religious contexts}

Because of the changing cultural and religious preferences of the population, palliative care professionals are being presented with needs and preferences they have not been exposed to before and which have not been integrated into their professional practices (Thomsen, 2014; Pentaris, 2016). Two key terms are used in this paper: cultural competence and religious literacy. The former refers to the enhancement of skills and abilities to better engage with different cultures (Sue and Sue, 2012), while the latter suggests the need for developing an appropriate language and understanding of the multitude of faiths in society in order to nurture positive professional practice (Dinham and Francis, 2015). Research literature shows that palliative care services across western countries are working to improve the access for patients with diverse ethnic backgrounds in their region (Jones, 2005; Clark and Phillips, 2010; Halm et al., 2012; Bellamy and Gott, 2013), and developing cultural competences and religious literacy is a means to achieve this end. The effectiveness of many of these approaches and the impact that palliative care has on the diverse identities of patients and relatives are yet to be assessed. 
An emerging discussion and the evaluation of models of cultural care and nurse education in cultural competence can be found in the research literature on end-of-life care, and a shift from a so called 'cook-book' approach to the acceptance of individual affiliation to culture and religion became a central focus point of research between 2000 and 2015 (Jones, 2005; Adames et al., 2014). However, the authors' (Thomsen, 2014; Pentaris, 2016) previous studies in Denmark and in the UK, respectively, found that in practice professionals are still requesting culture specific knowledge irrespective of their awareness of individual variation. Brown et al. (2013) opine that professional skills, confidence and information must be built along with the creation of flexible organizational structures. This is also highlighted by Huang, Yates and Prior (2009). If the organizational philosophy encourages cultural reflexivity and flexibility, it supports the professional development of cultural sensitivity. National guidelines in Denmark and England (Danish Health Authority, 2011; DH, 2009) stretch the importance of attention to cultural and religious differences in care; however, support is scarce and no mention of this can be found in the best practice catalogue (Danish Health Authority, 2012).

Religion and belief have also received increasing attention in death policies, end of life care and research over the last twenty years. To address these aspects of identity, Dinham and Francis (2015) explored the concept of religious literacy, referring to it as a fluid concept. The authors suggest that religious literacy refers to knowledge and understanding of various religious perspectives, as well as to how these are interpreted by individuals. Moreover, it implies a set of skills and abilities necessary to better respond to needs related to religion and belief. Therefore, the concept of religious literacy is of great importance to this project and will be used as a framework through which the findings can be discussed and understood.

This paper explores these challenges by analysing the way in which professional practitioners in palliative care respond to multi-ethnic and multi-religious patient groups. The authors have 
primarily explored current attitudes and perspectives of palliative care professionals in England and Denmark, in combination with cultural competence (Thomsen, 2014; Kim-Goodwin, Clarke, and Barton, 2001; Gunaratnam, 2008) and religious literacy (Dinham and Francis, 2015; Pentaris, 2016). This further exploration by comparison provides the opportunity to gain an in-depth understanding of how cultural and religious identities of patients in palliative and hospice care are integrated into professional practice, from a cross-national perspective.

\section{Methodology}

This qualitative comparative analysis (QCA) (Rihoux and Ragin, 2009) is concerned with the thorough review of the findings of two qualitative studies in England and Denmark, respectively (Thomsen, 2014; Pentaris, 2016). According to Spitzlinger (2006), a comparative analysis is an elaborate process in which qualitative outcomes are transfigured into a comprehensive conversation that explores themes in juxtaposition.

This paper draws on two previous studies. The first took place across hospices in England (Pentaris, 2016) and the second across hospice and palliative care settings in Denmark (Thomsen, 2014). The first study, based on 22 interviews, explored the religious literacy of palliative care professionals, drawing on the nation's migration history, and the second study, based on 15 interviews, explored how the migration history of patients impacts the care they receive and the overall care context. Table 1 shows the demographic characteristics of the research participants in both studies.

$<$ Table 1 somewhere here $>$

The first study employed a social constructivist approach and the second a hermeneutic approach (i.e. the exploration of people's understanding as informed by history and cultural viewpoints) (Gadamer 1986, 2007; Ricoeur 1974, 1981), while both explored the professionals' views from a heuristic perspective (i.e. a solution-finding approach) (Kleining and Witt, 2000). ). Both 
approaches set the context for choosing a semi-structured interview method, while both are compatible with the current analysis, for the following reason. In its attempt to compare two or more cases, QCA is inherently characterized by a hermeneutic approach; the acceptance that findings also reflect cultural and traditional viewpoints that are embedded in the culture under research (e.g. Rantala and Hellström, 2001).

The overarching principle that led to the present project is twofold. On the one hand, ethnic, cultural, and religious identities contribute to the construction of the individual's attitudes and stances. On the other, the concepts of ethnicity, culture, and religion are socially constructed themselves (Burr, 2015), which complicates the picture even further in end of life care.

First, the findings of the two studies were compared with regard to the way in which palliative care professionals respond to multi-ethnic and multi-faith patient groups. Both studies had explored this, which resulted in six different approaches. Next, data was coded separately with the aim to nuance the approaches by identifying empirical examples of the presented perspectives from each study. The exemplary quotes from the Danish study were then translated by the Danish researcher (LLT).

Analysing across studies and settings poses challenges in terms of language differences and different data material which was not originally collected with the aim of comparison. Different research questions guided the two studies in their different settings. These were spurred by different theoretical assumptions which contributed to shaping the data material differently. The authors have therefore discussed in detail the identified approaches and the quotes selected as examples of these. Further limitations of this qualitative comparative analysis are discussed at the end of the article.

\section{Findings}




\section{A comparative analysis: cultural and religious awareness}

The most prominent concepts that emerged from both studies were a general awareness and acknowledgement of both cultural and religious diversities among service users. Palliative care professionals assumed awareness of the characteristics of the multitude of religions and cultural traditions that act as significant frameworks of the experiences of death, dying and bereavement. To draw on the findings that can be useful in both the English and Danish settings, the analysis reported here focuses on shared concepts. Six shared practice-based approaches emerged when comparing the data from the two studies. The following table is a depiction of these.

$<$ Table 2 somewhere here $>$

Each approach will be discussed in the following sections, accompanied by representative quotes from both studies in order to illustrate such observations.

\section{The neutral approach}

In both studies, palliative care professionals employ a neutral approach when working with people from varying and different cultural and religious backgrounds. Professionals were found to signal their expertise and experience based on the idea that inclusivity and support for everyone, regardless of background and personal identities, is most efficiently promoted by a neutral perspective. Further, a neutral approach illustrates professionals' perceptions about roles and responsibilities between healthcare staff. Similarly, neutrality seems to mark professionalism and standards of practice.

My experience is that they will take care of that [religious and cultural needs] on their own.

They don't need that from me, as a doctor they need me for something medical, just like they need the home care team for assistive technologies and care. The religious and 
existential matters they will sort out on their own. I don't think we should worry so much about that. (General practitioner, DK).

Well, I think it has to do with other people in the hospice as well. If we talk about one tradition or a religion more, then people with different beliefs may be insulted. I do not know exactly, but we would prefer to remain distant from it, just to ensure that no one is favoured and definitely refer people to the chaplain (Hospice nurse, UK).

The quotes illustrate different rationales behind a neutral approach; on one hand, the professionals should focus on their area of expertise because this is what the patients want based on experience, and on the other hand, the professionals fear that focusing on religion would favour some groups over others. The neutral approach serves two purposes. First, it acts as a stabilizer of pertinent anxieties in palliative care professionals when working with people of cultures and religions they are unfamiliar with, thus preventing their practice from gradually jeopardizing the service user experience in this perspective. Nonetheless, a different form of jeopardy is apparent with this approach. Being neutral in one's approach weighs heavily on the service user experience. It stands against many service users' attitudes toward death, dying and bereavement, which are defined by their culture and/or religion (Parkes, Laungani, and Young, 2015).

\section{Universalistic approaches}

Both studies suggest that some professionals assumed that similarities existed among cultural groups, based on the thought that illness evokes the same questions and concerns across cultural groups; however, they asked the patients and families directly if they had certain needs or beliefs that should be taken into consideration (a more pragmatic approach, as will be discussed later). Similarly, professionals expressed generalized ideas about different religious and non-religious identities, but with the intention to further inquire about unique perceptions of respective faiths. 
The universalistic approach in some way resembles the neutral perspective for the following reason. Palliative care professionals employ the universalistic approach in order to take human similarities as their point of departure; the assumption that illness evokes the same basic suffering, fears and concerns across cultural and religious groups. The neutral approach satisfies the need to generalize but with no point of reference (i.e. religion or culture), which would be the case in the universalistic perspective. The difference between the neutral and universalistic approaches is that the former enlarges the idea of secular practice in palliative and hospice care (Thomsen, 2014), while the latter unifies culture or religion-specific knowledge without the need to distinguish amongst unique forms of identity.

We are very knowledgeable about faiths and stuff. We do so much training as well. I mean I am comfortable cause I know what Muslims do or need when someone is dying, and also you know if a Sikh comes here, we have been told about their traditions and what they mean so we will offer those services. For example, we will always make sure that the Muslim patient can get the right food (Hospice nurse, UK).

However, there may be differences that need to be taken into consideration, but these are private and not to be assumed or taken for granted. Professionals in the field, and across both nations, are to a large extent conscious of this, but for reasons that have not yet been researched tend to generalize.

This was apparent in the Danish study (Thomsen, 2014), partly as generalizations about patients with a migrant background when palliative care professionals were asked how the trajectories of patients of another ethnicity differ from trajectories of ethnic Danish patients. Most of the professionals first noted that the patients with another ethnic background are different because of their personal experience and personality just like ethnic Danish patients, but then pointed to universalistic characteristics such as; having big families, preferring non-disclosure, having faith 
in the medical system, and taking control over the dying context. It also appeared as a tendency that individuals were grouped with other people of different ethnic descent under the expression 'they'. One hospice sought to protect big families from discrimination by making a special space for them in which they could cook without disturbing the normal order of the hospice:

I sometimes get the feeling that the volunteer workers may feel that the presence of [other cultural practices] is disturbing the normal order of the hospice, and we feel that this is also the case with some relatives of other patients. Some may remark that 'they' take up a lot of space. So, we are currently creating a space for 'them' [ethnic minorities/people with big families], to try to protect 'them' from this. So, we also have a kitchen by the guest room so that 'they' can cook there too because it takes up a lot of space if 'they' are cooking Arabic foods and the entire hospice smells like garlic (Hospice nurse, DK).

Although the intention is an act of protection, it becomes unclear who the staff is actually trying to protect. Is it the normal order of the hospice and the ethnic Danish patients and relatives, or is it 'they'; are the big families of patients with another ethnic background left undisturbed to do what they need to do without having to feel the disapproval of volunteers and other relatives trying to conduct the normal order of the hospice? The universalistic element lies in the assumption of similarity in both 'they' and the other (ethnic Danish) patients and relatives, which is inherent in and externalized by this act of creating protective spaces which, in their own right, are discriminating.

\section{Pragmatic approaches}

An equally important outcome of this qualitative comparative analysis is the fact that palliative care professionals in both countries demonstrated the tension of addressing the pragmatic, which is an inherent element in health and death policies. Professionals consider knowledge of culture 
and religion a practical guide that informs the specifics of how to care for people from that background. In other words, both studies have concluded that, despite their willingness to further engage with knowledge that will enhance the understanding and skills required when working with diverse populations, professionals inquire about cultural and religious backgrounds in order to be able to accommodate the practical requirements of the service users. An example that illustrates this is inquiring about a patient's faith or culture as this might impact their diet.

They [patients] are always asked at the admission and during their initial assessment because we need to know what food to offer them, or whether they need the prayer rooms, and other reasons (Hospice doctor, UK).

This approach has been noted before in hospice care (Galanti, 2014), but is also reflected in end of life policies in the UK (Pentaris, 2016) and Denmark (Danish Health Authority, 2011). Pentaris (2016) has explored this issue, but not extensively. In his/her account, he/she identified the fact that death policies do not only blur literary boundaries by the terminology used; they also operationalize highly contested concepts, such as religion, in order to develop practical guidelines by which professional practice in palliative and hospice care progresses. In the Danish study (Thomsen, 2014), some of the palliative care professionals took a pragmatic approach, naturally, in their interaction with patients and relatives and found that the practical guidelines developed in the hospice setting to become constraining of their contact with patients and relatives as there were too many aspects to bear in mind which might not even be relevant to the patient in question.

I just read through the document because it has been a while and it is very elaborate. I would say...much of it is culture specific and I would say some of what is useful in the document is: 'remember that not all needs can be met'. But that goes for Danes too (Hospice nurse, DK) 
The Danish study concluded that in caring for patients with ethnic minority background, the more experienced palliative care professionals were more confident than less experienced Palliative care professionals in looking beyond the 'cook book' and ask families and patients how they might best be supported (Thomsen, 2014).

\section{Avoidant approaches}

Both studies have discussed extensively the concept of avoidance in palliative and hospice care. It was apparent that, due to lacking awareness of the significance of different, usually minority, cultures and religions, palliative care professionals tend to avoid engaging with those aspects of the service users' identities. This is complementary to the pragmatic approach noted. When faced with the uncertainty of the lack of their knowledge about a theme that intersects with their practice, professionals tend to shy away from it and use other resources that will support them in their practice. An example of this is the tendency to invite a chaplain into the care plan, regardless of whether or not the service user has requested such services. It is the notion of a person with a religious identity that drives this initiative.

Well if they believe in things that I do not know then my trying to talk to them about it might be rude, I think. It is...well...if I know someone is from a faith background I am not familiar with I can then signpost them to our chaplaincy services and they will talk about whatever they like to talk about (Hospice doctor, UK).

In the Danish study, an avoidant approach was showing as the avoidance of asking the patient about personal and biographical experiences, which is common with Danish patients.

It is difficult to determine if it is due to language barriers. That might be. I can imagine, however, that they would like to talk to their relatives - but not so much to us [the staff]. But I am not sure if it is because we do not invite them to talk, or if it is actually because it 
does take some effort and time to get around those things. It is not like we don't talk to them about it ever, about what they have... - but there might be a slight fear of contact, because: 'what did you escape from? -what is behind?' (Hospice doctor, DK).

The fear of contact that this professional mentions is related to traumatic experiences about migration which some professionals may not feel ready to handle. This may be an example of the irrational and visceral factors identified by Gunaratnam (2007), which may act as barriers to culturally sensitive care.

The avoidant approach, like the other approaches, is not representative of an absolute choice of how to deliver services in palliative and hospice care in England and Denmark. On the contrary, it represents an inevitable outcome from a multi-cultural and multi-faith environment, which does not have sufficient professional skills to address it.

\section{Domestic/Christian-centred approach}

Across both studies in this comparative analysis, professionals appeared to experience or interpret their practice through the lens of their own worldviews. In other words, various cultural and religious identities were primarily examined through the lenses of Christianity and the professional cultures in England and Denmark, respectively.

By and large, health care professionals in England demonstrated their knowledge and understanding of minority and other religions and non-religion through the lens of Christianity, the dominant religious faith in the country. This not only limits the experience of the health care professionals, but that of the service users as well.

We have a lot of people from other than Christianity religions and they have...they practice different things which we are fine with. I mean they believe in their God but it is the same as the Christian God (Hospice nurse, UK). 
We do talk with patients if they wish to talk. Or at least I can speak for myself. If they start having more fears and all that, about their situation, I will chat with them, if they want to, about God and Heaven, and no matter what religion they come from this is relevant to everyone (Hospice nurse, UK).

As regards assessing the patients' needs, a Christian centred approach appeared as a normative attitude to good and appropriate care as inherent in the palliative care frame.

We do try to listen to what they say and respect that. But then, when we have the dying person alone - which we rarely have in those families - we kind of try to figure out what their needs are. Perhaps it is just us sometimes who have this need to put it in words...yes, it is kind of in our [professional] culture (hospice doctor, DK.).

Also, a domestic approach as to how to handle the dead body appeared as a lens through which nurses judged the practices of a bereaved family.

And then she died. A group of women came along to give her a ritual wash. I was not there but it was quite chocking for the nurses present. We knew that it was taking place, but it was done on the cold bathroom floor because we did not have a separate room for this this was the only way, and they [the nurses] held back, but they really found it difficult to watch because they found it undignified. (Hospice nurse, DK).

This approach has serious implications as it denigrates the quality of care across palliative and hospice services. The indication is that acquired knowledge, skills and abilities to work with other faith groups is biased by the principles of the predominant religion and culture, which influence the ethics of the palliative care frame. Health care professionals seem to perceive other faith groups as something different than Christianity, and often as something lesser (Pentaris, 2016). The alternative and, according to the authors, most culturally sensitive attitude would be to have health 
care professionals experiencing the diverse faith and belief systems, as well as religiously oriented cultural traditions, as different but equal and as equally fit contexts for practicing palliative care. The Christian-centred approach is, however, a natural outcome if we consider the history of hospice and palliative care (Clark, 2002). The pillars for its development stemmed from Christianity and Cicely Saunders's strong connection with God and the Church of England (Clark, 2002). Holistic and interdisciplinary care took this connection into serious account when moving into the modern era of hospice care. In particular, spiritual care, as a core dimension of total pain (Saunders, 1996), was designed from a Christian perspective to care for people from any religion, yet in contemporary society, often with a particular focus on all other than Christianity religions, for which professionals needed to develop more skills and knowledge.

Last, this approach and attitude toward end of life care in general greatly challenge non-religion. Yet again, this may be an under-researched area. It is, however, very important to study this phenomenon; i.e. non-religious people's experiences are primarily understood through the framework of Christianity, which is in itself a contradicting element.

\section{The factualist approach}

An additional approach that was noted captured health care professionals who are willing to expand their knowledge of different cultures and religions. Both studies explored this further and concluded that health care professionals were interested in retrieving further factual knowledge about different groups. However, they did not consider the need for learning through engaging with this knowledge in ways by which they would develop a sound understanding of what this means and why it is important to service users.

For example, health care professionals in England suggested that they wish to learn more about more religions and expand their factual knowledge of what other religions do when someone dies. 
Despite its value, this knowledge may enhance the use of a universalistic or pragmatic approach, which would gradually undermine the need for a comprehensive understanding of lived religion (McGuire, 2008) and lived culture (Csordas, 1994), respectively:

Yes, and I will attend all sorts of training and will hear more about Muslims, for example, and Sikhs. And if I do not know much about Buddhism and their beliefs and practices in relation to death then I will speak to my manager and will go to a training or take an online course that tells you all the information you need to know (Hospice nurse, UK).

Equally, in the Danish study, some professionals only expressed the need for more knowledge so that they could acquire factual understanding of different religious practices about dying and death. I really look forward to that seminar because I think there is lots of ritual surrounding their death - some need a sheet to cover their head and such and who are they? And things like that - I really don't know (Home care nurse, DK).

Yet others had participated in cultural seminars over time and experienced a change in discourse and thus different approaches to cultural care; one professional had participated in a seminar with a factualist/universalistic approach in the 1990s and a later seminar in recent years in which lived religion and culture were at the centre.

It was 20 years ago, when I participated in my first seminar - 'dying across cultures' I think it was called. There was great interest in the topic during the first half of the 90 s because we started to receive more and more [ethnic minority patients]. This was a national seminar and I participated because I wished to know more. But it was very focused on divisions stereotypes - and; 'this is how it is done in Muslim culture', 'this is how it is done in Hindu culture', 'this is how their funeral is done', 'these are their mourning rituals'. I have carried this knowledge with me until recently when I participated in another seminar in which the 
teacher was contesting this approach, saying: 'It is not that stereotypical, they are individuals too' (Palliative care nurse, DK).

The source from which the professionals acquire their cultural and religious knowledge and literacy seems to be of central importance as many professionals have adopted the media representations of the culturally diverse society in which they live and do not have first-hand experience with people with a migrant background. This also indicates that training is essential to build basic cultural competences across services. Studies have also shown that a knowledge approach is not sufficient and that a practice dimension should support this for the participants to be able to apply this knowledge reflexively (Ekblad, Marttila, and Emilsson, 2000; Diver, Molassiotis, and Weeks, 2003; Halm et al., 2012).

\section{Discussion}

This qualitative comparative analysis found six practice-based approaches in palliative and hospice care which were common to Denmark and England. However, the reporting of these themes is, nonetheless, not complete. Palliative care professionals' attitudes and approaches are everchanging and subject to a series of events, as well as to the circumstances in the respective setting (Hawkins, Howard, and Oyebode, 2007). Further, the Danish study had primarily applied the frame of culture in its interviews, whereas the UK study applied the frame of religious literacy. This may have had an impact on the content of the approaches and on the way in which they were represented in the context of the two studies. Despite this, we found overall similarities as shown between the results of the two studies regarding how palliative care professionals respond to patients with a migrant background.

Returning to the discussion of services adapting to cultural diversity at the beginning of the article, it is important when discussing the approaches to consider the different layers of hospice and 
palliative settings that inform the practice, and by which the approaches have been identified; this is reminiscent of Goel's (2004) suggestions about organizational structure in healthcare.

The authors acknowledge three such layers (Figure 1). Organizational foundations refer to the overarching principles and structure of the organization, including its policies. Organizational culture reflects values and behaviour that are central for the organization, as well as the organizational norms. Last, professional refers to the individual palliative care professionals.

$<$ Figure 1 here $>$

In other words, professional attitudes and approaches toward the religious and cultural identities of service users are not static, but rather changeable this is partly due to changes in the knowledge available and partly due to changes in policies and the organizational culture. It is within these three layers that such attitudes are seen, and it is in the sphere of these three layers that palliative care professionals employ more than one approach.

According to Bradbury et al.'s (2012) work, professional approaches are subject to a commitment to lifelong learning. The latter is closely connected with the three layers suggested.

The different approaches that have been noted in hospice and palliative care practices intersect in various ways. Figure 2 shows the complicated relational network between the layers and professional approaches in hospice and palliative care settings.

$<$ Figure 2 here $>$

Each approach may be directly linked with one or more organizational layers. This is of significance as the link tells us what the source of information required for the development and implementation of this particular approach may be. To illustrate this, we will further discuss the relationship diagram (Figure 2) above.

Both the Christian-centred approach and the factualist approach are embedded within the organizational foundations of the settings in which the research of both studies was undertaken. 
The term "Christian-centred" is used because of the history of hospice care that derives primarily from Christianity and the Christian duty to care for the dying (Saunders, 1996), and "factualist" because of the policies of the organization and the identified intentions to expand knowledge and expertise. These intentions are mirrored in the other two layers that exist within the organizational foundations.

The Christian-centred approach is also found in the professional. Due to their personal religious belief or cultural heritage, individual palliative care professionals may be more or less prone to perceiving diversity through the lens of Christianity. In these cases, the latter is often perceived as a personal norm. Also, the factualist approach has been observed in the professional. Palliative care professionals indicate their willingness to learn more about more religions and cultures in order to acquire knowledge of different traditions and rituals. This approach, i.e. the factualist, is also seen in the organizational culture of the settings. It has become an organizational norm to pursue further training in order to develop more knowledge about religions and cultures that differ from the local norm. However, national studies have shown that despite the level of willingness to engage, current approaches by palliative care professionals are questionable and normative or, at times, denigrating to cultures or religions that differ from the local norm (e.g. Gunaratnam, 2007; Hart, Sainsbury, and Short, 1998; Thomsen, 2014; Pentaris, 2016). Other studies have shown that the palliative care frame implies a strong set of norms for 'a good death' which spring from a western ethics of a good death (Hart, Sainsbury, and Short, 1998; Owens and Randhawa, 2004). Palliative care professionals can only be expected to work from this frame unless they are given additional competences and an organisational structure within which to work with this frame in a flexible manner that includes diverse cultural and religious identities.

The pragmatic approach is seen in all three layers. A culture has existed of recording information pertinent to the service users' culture and religion in order to better address practical issues and 
dilemmas. An example of the above is blood transfusion, which has also been explored by Singelenberg (1990). Further, the remaining approaches, i.e. universalistic, avoidant and neutral, are all found in both the organizational culture of the settings and within individual professionals. Perhaps these are a result of major trends in reflexive modernity (Giddens, 1990; Bauman, 2000; Beck, 1997) and secularization, which are penetrating practices in modern organizations as well as professionalism. In this theoretical frame, the identified approaches to cultural diversity are ways of coping with ever changing conditions and knowledge, either through the bracketing of knowledge (avoidance and neutrality) or through attempts of reducing complexity (universalistic). An equally important point to be made is similar to Kirst-Ashman's (2008) argument. Organizational foundations, cultures and the people who constitute the organization are all interconnected; to some extent, their development over time is dependent on each element. In other words, the three organizational layers are also non-static.

The organizational structure may change due to changing social policies or changes in the senior management team. Such changes would have a direct effect on the organizational culture and the normative behaviour within the organization. Consequently, individual professionals are affected by these changes and will face the need to adapt to the new tactics of the organization.

Such a relational change greatly influences the approaches that palliative care professionals employ when working with service users from different cultures and religions. However, this is a supposition that requires further research and engagement in the field.

Generally, professional practices in palliative and hospice care in England and Denmark appear to mask inclusivity as neutrality and to explore the experiences of service users by separating them from their cultural and religious identities. The development of neutral approaches in palliative and hospice care coincides with the need to become inclusive of the diversified service user population. This raises a number of questions, however. A prominent question is the following; is neutrality 
the practice-based understanding of inclusivity in palliative and hospice care settings? In other words, such approaches challenge the current policy context (Danish Health Authority, 2011; DH, 2009) while perplexing the situation when examined in relation to the other approaches noted.

A fact file document is often found in a palliative care practice; this includes the collation of information for a specific cultural or religious group, which is later generalized to include a wider set of service users with a similar or identical identity. This trend is highly evident in both the Danish and English contexts. However useful this procedure may be, a fact file document assumes similarities across groups and individuals which may be true in some ways, but which are never without individual or lived variation.

\section{Conclusions}

It follows from the above analysis and experiences derived from the individual studies that the mainly bottom-up approach to developing cultural competences and religious literacy cannot stand alone. All three layers described and discussed above must be active agents in developing these skills and competences. Changes in the organizational culture must be supported by changes in social policies, and changes in professional attitudes and practices must be supported by changes in the organizational culture. This calls for further research into the needs for policy and organizational changes that can support and develop the cultural sensitivity which is present in the attitudes and awareness of health care professionals, but which is not well accommodated in practice, partly because of lacking organizational and policy support. Moreover, additional research into the identities and lived culture of service users is also of importance to the development of the culture-sensitive service provision adapted to individual needs which is vital in palliative care. 


\section{Acknowledgements}

The authors would like to thank all research participants who offered their experience and insights during the undertaking of both projects this paper draws on. Also, the authors would like to extend their gratitude to Anne Deehan for her most valuable comments on a drafted version of this paper.

\section{References}

Adames, H. Y., Chavez-Dueñas, N. Y., Fuentes, M. A., Salas, S. P., \& Perez-Chavez, J. G. (2014). Integration of Latino/a Cultural Values into Palliative Health Care: A Culture Centered Model. Palliative \& Supportive Care, 12(2), 149-157.

Altschuler, J. (2016). Migration, Illness and Healthcare. New York, NY: Palgrave Macmillan.

Bauman, Z. (2000). Liquid Modernity. Oxford: Polity Press.

Beck, U. (1997). Risk Society: Towards a New Modernity. London: Sage.

Bellamy, G., \& Gott, M. (2013). What are the Priorities for Developing Culturally Appropriate Palliative and End-Of-Life Care for Older People? The Views of Healthcare Staff working in New Zealand. Health \& Social Care in the Community, 21(1), 26-34.

Berger, P. L., \& Huntington, S. P. (2002). Many Globalizations: Cultural Diversity in the Contemporary World. Oxford: Oxford University Press.

Bradbury, H., Frost, N., Kilminster, S., \& Zukas, M. (eds). (2012). Beyond Reflective Practice: New Approaches to Professional Lifelong Learning. London: Routledge.

Brown, E., Patel, R., Kaur, J., \& Coad, J. 2013. The Interface Between South Asian Culture and Palliative Care for Children, Young People, and Families-a Discussion Paper. Issues in Comprehensive Pediatric Nursing, 36(1/2), 120-143.

Burr, V. (2015). Social Constructionism. London: Routledge.

Clark, D. (2002). Cicely Saunders: Founder of the Hospice Movement: Selected Letters 1959-1999. 
Oxford: Clarendon Press.

Clark, K., \& Philips, J. (2010). End of Life Care - The Importance of Culture and Ethnicity. Australian Family Physician, 39(4), 210-213.

Csordas, T. J. (ed). (1994). Embodiment and Experience: The Existential Ground of Body and Self. Cambridge: Cambridge University Press.

Danish Health Autority. (2012). Sundhedsstyrelsen. Katalog over Bedste Praksis for Palliative Indsatser. København: Sundhedsstyrelsen.

Danish Health Autority. (2011). Sundhedsstyrelsen. Anbefalinger for den Palliative Indsats. København: Sundhedsstyrelsen.

Department of Health (DH). (2009). Spiritual Care at the End of Life: A Systematic Review of the Literature. London: Department of Health.

Dinham, A., \& Francis, M. eds. (2015). Religious Literacy in Policy and Practice. Bristol: Policy Press.

Diver, F., Molassiotis, A., \& Weeks, L. (2003). The Palliative Care Needs of Ethnic Minority Patients: Staff Perspectives. International Journal of Palliative Nursing, 9(8), 343-51.

Ejernæs, A. (2014). Det etnisk mangfoldige samfund. In B. Grevem, A. Jørgensen, \& E. L. Larsen (Eds.), Det Danske Samfund. Hans Reitzels Forlag (pp.), København: Hans Reitzels Forlag.

Ekblad, S., Marttila, A., \& Emilsson, M. (2000). Cultural Challenges in End-Of-Life Care: Reflections from Focus Groups' Interviews with Hospice Staff in Stockholm. Journal of Advanced Nursing, 31(3), 623-30.

Gadamer, H. G. (2007). The Gadamer reader: A Bouquet of the Later Writings. Evanston, IL: Northwestern University Press.

Gadamer, H. G. (1986). The Relevance of the Beautiful and Other Essays. Cambridge: Cambridge University Press. 
Galanti, G. A. (2014). Caring for Patients from Different Cultures. Pennsylvania: University of Pennsylvania Press.

Giddens, A. (1990). The Consequences of Modernity. Cambridge: Polity Press \& Blackwell.

Goel, S. L. (2004). Health Care Organisation and Structure. Michigan: Deep and Deep Publications.

Gunaratnam, Y. (2008). From Competence to Vulnerability: Care, Ethics, and Elders from Racialized Minorities. Mortality, 13(1), 24-41.

Gunaratnam, Y. (2007). Intercultural Palliative Care: Do We need Cultural Competence? International Journal of Palliative Nursing, 13(10), 470-7.

Halm, M. A., Evans, R., Wittenberg, A., \& Wilgus, E. (2012). Broadening Cultural Sensitivity at the End of Life. Holistic Nursing Practice, 26(6), 335-349.

Hansen, R. (2003). Migration to Europe since 1945: Its History and its Lessons. The Political Quarterly, 74(s1), 25-38.

Hart, B., Sainsbury, P., \& Short, S. (1998). “Whose Dying?”: A Sociological Critique of the Good Death. Mortality, 3(1), 65-77.

Hawkins, A. C., Howard, R. A., \& Oyebode, J. R. (2007). Stress and Coping in Hospice Nursing Staff. The Impact of Attachment Styles. Psycho Oncology, 16(6), 563-572.

Hickman, M., Mai, N., \& Crowley, H. (2012). Migration and Social Cohesion in the UK. Basingstoke: Pallgrave Macmillan.

Huang, Y.-L., Yates, P., \& Prior, D. (2009). Factors influencing Oncology Nurses' Approaches to Accommodating Cultural Needs in Palliative Care. Journal of Clinical Nursing, 18(24), 3421-9. Jones, K. (2005). Diversities in Approach to End-Of-Life: A View from Britain of the Qualitative Literature. Journal of Research in Nursing, 10(4), 431-454. 
Kim-Goodwin, Y. S., Clarke, P. N., \& Barton, L. (2001). A Model for the Delivery of Culturally Competent Community Care. Journal of Advanced Nursing, 35(6), 918-925.

Kirst-Ashman, K. (2008). Human Behavior, Communities, Organizations, and Groups in the Macro Social Environment: An Empowerment Approach. Belmont, CA: Cengage Learning.

Kleining, G., \& Witt, H. (2000). The Qualitative Heuristic Approach: A Methodology for Discovery in Psychology and the Social Sciences. Rediscovering the Method of Introspection as an Example [19 paragraphs]. Forum Qualitative Sozialforschung/ Forum: Qualitative Social Research, 1(1), Art 13 http://nbn-resolving.de/urn:nbn:de:0114-fqs0001136.

McGuire, M. B. (2008). Lived Religion: Faith and Practice in Everyday Life. Oxford: Oxford University Press.

Mikkelsen, F. (2008). Indvandring og Integration. Forlag: Akademisk Forlag.

Owens, A., \& Randhawa, G. (2004). 'It's Different from my Culture; They're Very Different': Providing Community-Based, 'Culturally Competent' Palliative Care for South Asian People in the UK. Health and Social Care in the Community, 12(5), 414-421.

Parkes, C. M., Laungani, P., \& Young, W. (eds). (2015). Death and Bereavement Across Cultures. New York, NY: Routledge.

Rantala, K., \& Hellström, E. (2001). Qualitative Comparative Analysis and a Hermeneutic Approach to Interview Data. International Journal of Social Research Methodology, 4(2), 87100.

Rechel, B., Mladovsky, P., Devillé, W., Rijks, B., Petrova-Benedict, R., \& McKee, M. (2011). Migration and Health in the European Union. London: European Observatory on Health Systems and Policies Series.

Ricoeur, P. (1981). Hermeneutics and the Human Sciences: Essays on Language, Action and Interpretation. Cambridge: Cambridge University Press. 
Ricoeur, P. (1974). Metaphor and the Main Problem of Hermeneutics. New Literary History, 6(1), 95-110.

Rihoux, B., \& Ragin, C. C. (2009). Configurational Comparative Methods: Qualitative Comparative Analysis (QCA) and Related Techniques. Thousand Oaks, CA: Sage.

Saunders, C. (1996). A Personal Therapeutic Journey. British Medical Journal, 323(7072), 15991601.

Singelenberg, R. (1990). The Blood Transfusion Taboo of Jehovah's Witnesses: Origin, Development and Function of a Controversial Doctrine. Social Science Medicine, 31(4), 515-523. Spitzlinger, R. (2006). Mixed Method Research-Qualitative Comparative Analysis. Wien: Grin. Sue, D. W., \& Sue, D. (2012). Counseling the Culturally Diverse: Theory and Practice. Oxford, UK: John Wiley \& Sons.

Thomsen, L. L. 2014. When a "stranger" dies. (Doctoral dissertation, Aalborg University, Aalborg)

Timmins, N. (1995). The Five Giants: A Biography of the Welfare State. London, UK: Harper Collins.

Walter, T. (2012). Why Different Countries manage Death Differently: A Comparative Analysis of Modern Urban Societies. The British Journal of Sociology, 63(1), 123-145.

\section{References}

Adames, H. Y., Chavez-Dueñas, N. Y., Fuentes, M. A., Salas, S. P., Perez-Chavez, J. G. 2014. "Integration of Latino/a Cultural Values into Palliative Health Care: A Culture Centered Model." Palliative \& Supportive Care 12 (2): 149-157.

Altschuler, J. 2016. Migration, Illness and Healthcare. New York, NY: Palgrave Macmillan. Bauman, Z. 2000. Liquid Modernity. Oxford: Polity Press. 
Beck, U. 1997. Risk Society: Towards a New Modernity. London: Sage.

Bellamy, G., and Gott, M. 2013. "What are the Priorities for Developing Culturally Appropriate Palliative and End-Of-Life Care for Older People? The Views of Healthcare Staff working in New Zealand." Health \& Social Care in the Community 21 (1): 26-34.

Berger, P. L., and Huntington, S. P. 2002. Many Globalizations: Cultural Diversity in the Contemporary World. Oxford: Oxford University Press.

Bradbury, H., Frost, N., Kilminster, S., and Zukas, M. eds. 2012. Beyond Reflective Practice: New Approaches to Professional Lifelong Learning. London: Routledge.

Brown, E., Patel, R., Kaur, J., and Coad, J. 2013. “The Interface Between South Asian Culture and Palliative Care for Children, Young People, and Families-a Discussion Paper." Issues in Comprehensive Pediatric Nursing 36 (1/2): 120-143.

Burr, V. 2015. Social Constructionism. London: Routledge.

Clark, D. 2002. Cicely Saunders: Founder of the Hospice Movement: Selected Letters 1959-1999. Oxford: Clarendon Press.

Clark, K., and Philips, J. 2010. "End of Life Care - The Importance of Culture and Ethnicity." Australian Family Physician 39 (4): 210-213.

Csordas, T. J. ed. 1994. Embodiment and Experience: The Existential Ground of Body and Self. Cambridge: Cambridge University Press.

Danish Health Autority. 2012. Sundhedsstyrelsen. Katalog over Bedste Praksis for Palliative Indsatser. København: Sundhedsstyrelsen.

Danish Health Autority. 2011. Sundhedsstyrelsen. Anbefalinger for den Palliative Indsats. København: Sundhedsstyrelsen.

Department of Health (DH). 2009. Spiritual Care at the End of Life: A Systematic Review of the Literature. London: Department of Health. 
Dinham, A., and Francis, M. eds. 2015. Religious Literacy in Policy and Practice. Bristol: Policy Press.

Diver, F., Molassiotis, A., and Weeks, L. 2003. "The Palliative Care Needs of Ethnic Minority Patients: Staff Perspectives." International Journal of Palliative Nursing 9 (8): 343-51.

Ejernæs, A. 2014. “Det etnisk mangfoldige samfund.” In Det Danske Samfund. Hans Reitzels Forlag, edited by B. Grevem, A. Jørgensen, and E. L. Larsen, København: Hans Reitzels Forlag. Ekblad, S., Marttila, A., and Emilsson, M. 2000. "Cultural Challenges in End-Of-Life Care: Reflections from Focus Groups' Interviews with Hospice Staff in Stockholm." Journal of Advanced Nursing 31 (3): 623-30.

Gadamer, H. G. 2007. The Gadamer reader: A Bouquet of the Later Writings. Evanston, IL: Northwestern University Press.

Gadamer, H. G. 1986. The Relevance of the Beautiful and Other Essays. Cambridge: Cambridge University Press.

Galanti, G. A. 2014. Caring for Patients from Different Cultures. Pennsylvania: University of Pennsylvania Press.

Giddens, A. 1990. The Consequences of Modernity. Cambridge: Polity Press \& Blackwell.

Goel, S. L. 2004. Health Care Organisation and Structure. Michigan: Deep and Deep Publications. Gunaratnam, Y. 2008. "From Competence to Vulnerability: Care, Ethics, and Elders from Racialized Minorities." Mortality 13 (1): 24-41.

Gunaratnam, Y. 2007. "Intercultural Palliative Care: Do We need Cultural Competence?" International Journal of Palliative Nursing 13 (10): 470-7.

Halm, M. A., Evans, R., Wittenberg, A., and Wilgus, E. 2012. "Broadening Cultural Sensitivity at the End of Life." Holistic Nursing Practice 26 (6): 335-349.

Hansen, R. 2003. "Migration to Europe since 1945: Its History and its Lessons." The Political 
Quarterly 74 (s1): 25-38.

Hart, B., Sainsbury, P., and Short, S. 1998. ““"Whose Dying?”: A Sociological Critique of the Good Death." Mortality 3 (1): 65-77.

Hawkins, A. C., Howard, R. A., and Oyebode, J. R. 2007. "Stress and Coping in Hospice Nursing Staff. The Impact of Attachment Styles." Psycho Oncology 16 (6): 563-572.

Hickman, M., Mai, N., and Crowley, H. 2012. Migration and Social Cohesion in the UK. Basingstoke: Pallgrave Macmillan.

Huang, Y.-L., Yates, P., and Prior, D. 2009. 'Factors influencing Oncology Nurses' Approaches to Accommodating Cultural Needs in Palliative Care.” Journal of Clinical Nursing 18 (24): 34219.

Jones, K. 2005. "Diversities in Approach to End-Of-Life: A View from Britain of the Qualitative Literature." Journal of Research in Nursing 10 (4): 431-454.

Kim-Goodwin, Y. S., Clarke, P. N., and Barton, L. 2001. "A Model for the Delivery of Culturally Competent Community Care." Journal of Advanced Nursing 35 (6): 918-925.

Kirst-Ashman, K. 2008. Human Behavior, Communities, Organizations, and Groups in the Macro Social Environment: An Empowerment Approach. Belmont, CA: Cengage Learning.

Kleining, G., and Witt, H. 2000. "The Qualitative Heuristic Approach: A Methodology for Discovery in Psychology and the Social Sciences. Rediscovering the Method of Introspection as an Example [19 paragraphs]." Forum Qualitative Sozialforschung/ Forum: Qualitative Social Research 1 (1): Art 13 http://nbn-resolving.de/urn:nbn:de:0114-fqs0001136.

McGuire, M. B. 2008. Lived Religion: Faith and Practice in Everyday Life. Oxford: Oxford University Press.

Mikkelsen, F. 2008. Indvandring og Integration. Forlag: Akademisk Forlag. 
Owens, A., and Randhawa, G. 2004. “'It's Different from my Culture; They're Very Different': Providing Community-Based, 'Culturally Competent' Palliative Care for South Asian People in the UK." Health and Social Care in the Community 12 (5): 414-421.

Parkes, C. M., Laungani, P., and Young, W. eds. 2015. Death and Bereavement Across Cultures. New York, NY: Routledge.

Pentaris, P. 2016. Religious Literacy in End Of Life Care: Challenges and Controversies. (PhD Dissertation, Goldsmiths University of London, London, UK).

Rantala, K., and Hellström, E. 2001. "Qualitative Comparative Analysis and a Hermeneutic Approach to Interview Data.” International Journal of Social Research Methodology 4 (2): 87 100.

Rechel, B., Mladovsky, P., Devillé, W., Rijks, B., Petrova-Benedict, R., and McKee, M. 2011. Migration and Health in the European Union. London: European Observatory on Health Systems and Policies Series.

Ricoeur, P. 1981. Hermeneutics and the Human Sciences: Essays on Language, Action and Interpretation. Cambridge: Cambridge University Press.

Ricoeur, P. 1974. "Metaphor and the Main Problem of Hermeneutics.” New Literary History 6 (1): 95-110.

Rihoux, B., and Ragin, C. C. 2009. Configurational Comparative Methods: Qualitative Comparative Analysis (QCA) and Related Techniques. Thousand Oaks, CA: Sage.

Saunders, C. 1996. “A Personal Therapeutic Journey.” British Medical Journal 323 (7072): 15991601.

Singelenberg, R. 1990. "The Blood Transfusion Taboo of Jehovah's Witnesses: Origin, Development and Function of a Controversial Doctrine.” Social Science Medicine 31 (4): 515-523. Spitzlinger, R. 2006. Mixed Method Research-Qualitative Comparative Analysis. Wien: Grin. 
Sue, D. W., and Sue, D. 2012. Counseling the Culturally Diverse: Theory and Practice. Oxford, UK: John Wiley \& Sons.

Thomsen, L. L. 2014. When a "stranger" dies. (Doctoral dissertation, Aalborg University, Aalborg)

Timmins, N. 1995. The Five Giants: A Biography of the Welfare State. London, UK: Harper Collins.

Walter, T. 2012. "Why Different Countries manage Death Differently: A Comparative Analysis of Modern Urban Societies.” The British Journal of Sociology 63 (1): 123-145.

Table 1: Research participants by country

\begin{tabular}{l|ccc}
\multicolumn{1}{l}{ England } & Denmark & Total \\
\hline Gender & 9 & 1 & 10 \\
Male & 13 & 14 & 27 \\
Female & & & $\mathrm{n} / \mathrm{a}$ \\
Age & 14 & $\mathrm{n} / \mathrm{a}$ & $\mathrm{n} / \mathrm{a}$ \\
$>50$ & 5 & $\mathrm{n} / \mathrm{a}$ & $\mathrm{n} / \mathrm{a}$ \\
$35-49$ & 3 & $\mathrm{n} / \mathrm{a}$ & \\
$<35$ & & & 9 \\
Discipline & 5 & 4 & 15 \\
Physician & 8 & 7 & 5 \\
Nurse & 4 & 1 & 3 \\
Social Worker & 3 & 0 & 2 \\
Physiotherapist & 2 & 0 & 1 \\
Occupational Therapist & 0 & 1 & 1 \\
Chaplain & 0 & 1 & 1 \\
Music Therapist & 0 & 1 &
\end{tabular}

Table 2: Practice-based approaches in Palliative and Hospice Care in England and Denmark

\begin{tabular}{|l|l|l|}
\hline Approaches & Description & Example \\
\hline
\end{tabular}




\begin{tabular}{|c|c|c|}
\hline Neutral & Masking neutrality as inclusivity & $\begin{array}{l}\text { Rejecting a conversation } \\
\text { about a particular faith as it } \\
\text { may show exclusivity of } \\
\text { others }\end{array}$ \\
\hline Universalistic & $\begin{array}{l}\text { Generalization of perceptions across } \\
\text { the same cultural or religious } \\
\text { background }\end{array}$ & $\begin{array}{l}\text { Assuming that all Muslim } \\
\text { patients pray exactly the same } \\
\text { number of times within a day }\end{array}$ \\
\hline Pragmatic & $\begin{array}{l}\text { Addressing culture and religion } \\
\text { specific knowledge as a guide to meet } \\
\text { needs }\end{array}$ & $\begin{array}{l}\text { Asking about } r \text { one's } \\
\text { background which will } \\
\text { provide knowledge of their } \\
\text { dietary requirements }\end{array}$ \\
\hline Avoidant & $\begin{array}{l}\text { Avoiding to engage with cultures or } \\
\text { religions and non-religion to limit the } \\
\text { risk of associating with something that } \\
\text { is unknown and which professionals } \\
\text { feel uncertain about }\end{array}$ & $\begin{array}{l}\text { Actively avoiding to respond } \\
\text { to questions that seek support } \\
\text { on a cultural or religious basis. }\end{array}$ \\
\hline $\begin{array}{l}\text { Domestic/Christian- } \\
\text { centred }\end{array}$ & $\begin{array}{l}\text { Approaching practice with various } \\
\text { faiths through the lens of domestic } \\
\text { beliefs and practices, such as } \\
\text { Christianity }\end{array}$ & $\begin{array}{l}\text { Addressing other religions or } \\
\text { cultures in comparison to the } \\
\text { domestic religion or culture, } \\
\text { and often as inferior }\end{array}$ \\
\hline Factualist & $\begin{array}{l}\text { Showing a willingness to expand } \\
\text { knowledge about other cultures and } \\
\text { religions than the local norms }\end{array}$ & $\begin{array}{l}\text { Health care professionals } \\
\text { engaging in reading more } \\
\text { about more religions and } \\
\text { cultures - enhancing their } \\
\text { factual knowledge }\end{array}$ \\
\hline
\end{tabular}


Figure 1: Layers of Hospice and Palliative Care Settings

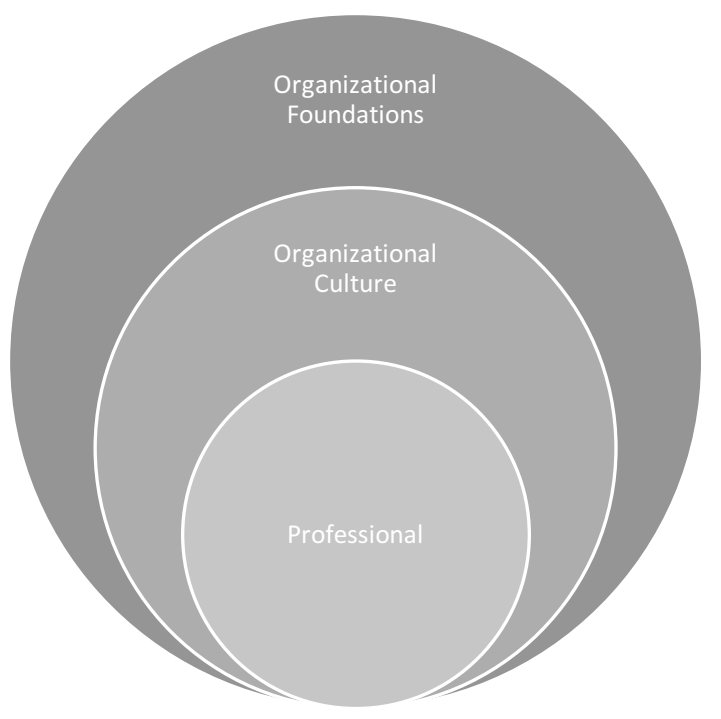

Figure 2: Hospice \& palliative care practice-based approaches in relation to the organizational layers

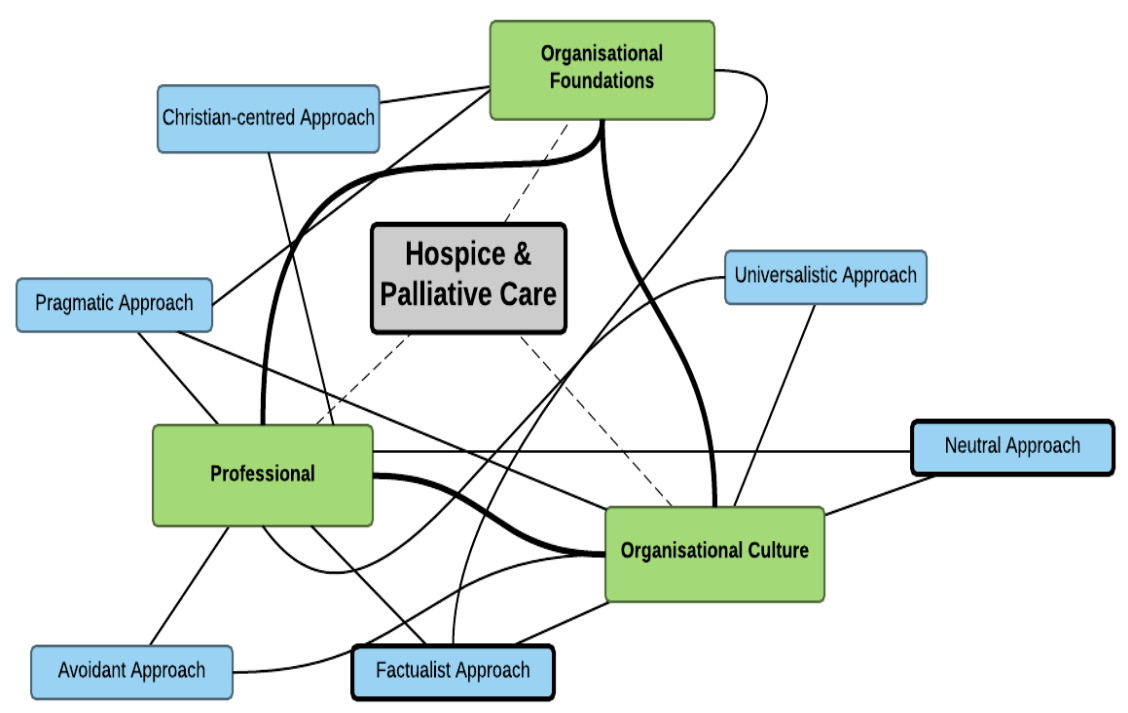

